\title{
Exposure to Repeated, Intermittent $d$-amphetamine Induces Sensitization of HPA Axis to a Subsequent Stressor
}

\author{
Alasdair M. Barr, B.A. Candace E. Hofmann, M.A., Joanne Weinberg, Ph.D., \\ and Anthony G. Phillips, Ph.D.
}

Previous studies have demonstrated that exposure to psychostimulant drugs can produce a lasting crosssensitization to the behavioral effects of stress. The main purpose the present study was, therefore, to determine the effects of psychostimulant cross-sensitization on the stressinduced release of adrenocorticotropic hormone (ACTH) and corticosterone (CORT). Rats were given a series of injections of $\mathrm{d}$-amphetamine or vehicle in a regimen that has been shown previously to induce cross-sensitization to a stressor. After two weeks, half the animals in the drug and vehicle-treated conditions were subjected to $30 \mathrm{~min}$ restraint stress; the remaining animals served as nonstressed controls. Animals were then sacrificed and trunk blood was assayed for CORT and ACTH. Prior damphetamine had no effect upon levels of CORT and ACTH in the non-stressed animals. Following 30 min restraint stress, however, levels of both hormones were significantly higher in drug-treated animals compared to controls. A second experiment confirmed behavioral sensitization to the current schedule of $\mathrm{d}$-amphetamine injections, and demonstrated neuroendocrine sensitization of ACTH and CORT to a subsequent drug challenge. The augmented release of CORT and ACTH observed in $\mathrm{d}$-amphetaminetreated rats might have important implications for human disorders in which processes resembling neurochemical sensitization have been hypothesized to play an etiological role.

[Neuropsychopharmacology 26:286-294, 2002] (C) 2002 American College of Neuropsychopharmacology. Published by Elsevier Science Inc.
KEY WORDS: Amphetamine; Adrenocorticotropic hormone; Corticosterone; Rat; Stress; Sensitization

Adverse experiences are an anticipated aspect of life for most organisms (Goldstein 1990; Henry 1992; Folkow

Department of Psychology (AMB, CEH, JW, AGP), Department of Anatomy (CEH, JW), Department of Psychiatry (AGP), University of British Columbia, Vancouver, Canada

Address correspondence to: Anthony G. Phillips, Department of Psychology, 2136 West Mall, University of British Columbia, Vancouver, Canada, V6T1Z4, Tel.: 604-822-3245, Fax: 604-822-6923, E-mail: aphillips@cortex.psych.ubc.ca

Received August 31, 2000; revised March 28, 2001; accepted June 5, 2001.

Online publication: 6/6/01 at www.acnp.org/citations/Npp 060601130
1997; Sapolsky et al. 2000). Consequently, a complex set of homeostatic mechanisms, which include endocrine, metabolic, immune and neural defensive reactions, has evolved to ensure that the harmful effects of most stressors rarely exceed an organism's capacity to cope with them (Johnson et al. 1992; McEwen 1998). In certain instances, however, these homeostatic mechanisms become compromised, such as after chronic hypothalamicpituitary-adrenal (HPA) axis activation or prolonged stress, and the noxious effects of stressors then become exaggerated (McEwen 1998; Brown et al. 1999). The emerging concept of a physiological and psychological cost involved with chronically heightened neuroendocrine arousal to environmental stimuli, often referred to as "allostatic load", is seeing increased interest as an impor- 
tant factor in the development of many forms of human disease (McEwen 2000; Koob and Le Moal 2001). A wealth of evidence suggests that an increased reactivity to stressors and/or the inability to respond effectively and appropriately to stressors plays an important role in the development and expression of many forms of mental illness (Ehlert and Straub 1998; Kreek and Koob 1998; Dohrenwend 2000; Heim et al. 2000). Clearly, a better understanding of the underlying neurobiology of this sensitivity to stressors may help in the prophylaxis and treatment of these disorders.

Animal and human studies have demonstrated that environmental manipulation, such as exposure to alcohol or stress during the pre- and early postnatal period (Liang and Boyce 1993; Weinberg et al. 1996; Day et al. 1998), can modify an organism's response to stressors. Such manipulations may lead to an increased reactivity to stressors ("sensitization"), which can be expressed both behaviourally and neurochemically (Pitman et al. 1990; Badiani et al. 1996; Pani et al. 2000). One form of sensitization involves the capacity of psychostimulant drugs, such as cocaine and $d$-amphetamine, to react interchangeably with stressors in producing an augmented behavioral response (Antelman et al. 1980; Prasad et al. 1998). This type of cross-sensitization appears to be bidirectional, in that previous exposure to a psychostimulant drug can sensitize the behavioral response to an ensuing stressor, and vice versa. However, the capacity of psychostimulant drugs to cross-sensitize neurendocrine responses to subsequent stressors through effects on the HPA axis remains undetermined. This issue is important, as the HPA axis plays a crucial role in the homeostasis of the organism, and a disruption of the normal functioning of the HPA axis could lead to many of the types of symptoms associated with "allostatic load". As sensitization-like processes have been implicated in the development of several major psychiatric disorders (Post 1992; Duncan et al. 1999; Laruelle 2000) that are frequently associated with dysregulation of the HPA axis (Plotsky et al. 1998; Muck-Seler et al. 1999; Heim et al. 2000), the link between glucocorticoid hormone release in response to stress and sensitization needs to be clarified.

The main purpose of the present study, therefore, was to determine the effects of psychostimulant cross-sensitization on the stress-induced release of adrenocorticotropic hormone (ACTH) and corticosterone (CORT). We utilized an established rodent model of cross-sensitization (Hamamura and Fibiger 1993), in which rats were administered daily injections of $d$-amphetamine over 14 days, and subsequently remained undisturbed for an additional two weeks. At the end of this period, the animals were subjected to mild restraint stress, and levels of ACTH and CORT were measured. We also conducted a second experiment which confirmed the results of earlier studies showing that previous exposure to $d$-amphetamine induces behavioral and neurendo- crine sensitization to a subsequent drug challenge (Schmidt et al. 1995; Vanderschuren et al. 1999), by measuring behavioral stereotypy and ACTH and CORT levels in previously sensitized animals.

\section{METHODS}

\section{Experiment 1: Effect of Exposure to $d$-amphetamine on HPA Activity in Response to a Subsequent Stressor}

Animals. Forty adult male Wistar rats (250-275g; Animal Care Centre, University of British Columbia, Vancouver, BC) were pair-housed in polycarbonate cages $(24 \times$ $16 \times 46 \mathrm{~cm})$. All animals were maintained on a 12-hr light-dark cycle (lights on 7 A.M. to 7 P.M.). The colony room temperature was maintained at $20^{\circ} \mathrm{C}\left( \pm 1^{\circ} \mathrm{C}\right)$ and rats had unlimited access to food (Purina Rat Chow) and water. All experimental procedures were conducted in accordance with the guidelines provided by the Canadian Council on Animal Care, the University of British Columbia Animal Care Committee and the NIH Guidelines for the Care and Use of Laboratory Animals.

Drug Treatment. Animals were randomly assigned to one of four groups ( $n=10$ per group). Two of these groups were administered a series of injections of $d$-amphetamine (Smith-Kline Beecham, Oakville, ON) based upon a protocol that had been shown previously to induce both behavioural and neurochemical sensitization to a stressor (Hamamura and Fibiger 1993). The regimen consisted of single daily intraperitoneal injections of $d$-amphetamine $(2 \mathrm{mg} / \mathrm{kg}$ ) for seven days, followed by single daily injections of a higher dose of the drug $(4 \mathrm{mg} / \mathrm{kg})$ for an additional seven days. The remaining two groups received a similar regimen of vehicle injections (isotonic saline $-1 \mathrm{~mL} / \mathrm{kg}$ ). All injections took place in the animals' home cage between 9 and 10 A.M., and all animals remained undisturbed for two weeks following the final injection, except for weekly weighing and cage changing.

Stress Procedure. Two weeks after the final drug or vehicle injection, one group of rats that had received $d$-amphetamine, and one that had received only saline, were removed sequentially in pairs from the housing colony to an adjoining test room. These rats were subjected to $30 \mathrm{~min}$ of restraint stress, by placing them into individual polyethylene restraining tubes $(6 \mathrm{~cm}$ diameter $\times 20 \mathrm{~cm}$ in length, with four holes in the front and an opening at the back for the tail). Immediately after restraint, animals were quickly removed from the restraining tubes and killed by decapitation. The remaining two groups of animals ( $d$-amphetamine- and vehicletreated) served as non-stressed (basal) controls. They were quietly removed from the housing colony in pairs, in counterbalanced order, and quickly decapitated. All animal handling procedures were conducted between 
8 and 10:30 A.M., when rats' CORT levels are at their nadir. Trunk blood was collected in ice cold polystyrene tubes containing $7.5 \mathrm{mg}$ EDTA and $1000 \mathrm{KIU}$ aprotinin. Blood was centrifuged at $3600 \times \mathrm{g}$ for $10 \mathrm{~min}$ at $4^{\circ} \mathrm{C}$ and plasma extracted and stored in polypropylene tubes at $-70^{\circ} \mathrm{C}$ until assayed for ACTH and CORT. The spleen, thymus and adrenal glands were removed from all animals, and cleaned and weighed for comparison.

Hormone Measurements. Total CORT (bound plus free) was measured by radioimmunoassay (RIA) using our adaptation (Weinberg and Bezio 1987) of the method of Kaneko et al. (1981). Antiserum was obtained from Immunocorp, Montreal, $\mathrm{PQ}$, Canada and tracer was obtained from Mandel Scientific, Guelph, ON, Canada. Dextran coated charcoal was used to absorb and precipitate free steroids after incubation. The intra and interassay coefficients of variation were $1.55 \%$ and $4.26 \%$, respectively.

ACTH was assayed using a modification of the DiaSorin RIA kit (American Standard Company; Stillwater, MN, USA). All reagent volumes were halved and $50 \mu \mathrm{l}$ of plasma per sample was used. The mid-range intra and interassay coefficients of variation were $3.9 \%$ and $6.5 \%$, respectively. One sample was spoiled (amphetamine/stress conditions) and had to be excluded from further analysis.

\section{Experiment 2: Effect of Exposure to $d$-amphetamine on HPA Activity in Response to Subsequent Drug Challenge}

Animals and Drug Treatment. Twenty adult male Wistar rats $(250-275 \mathrm{~g})$ were randomly assigned into two groups $(n=10$ per group). One of these groups was administered the series of injections of $d$-amphetamine as described in Experiment 1 . The remaining group received a similar regimen of injections, but with vehicle (isotonic saline $-1 \mathrm{ml}$ / $\mathrm{kg}$ ). All animals remained undisturbed for two weeks following the final injection, except for weekly weighing and cage changing.

Drug Challenge. Two weeks after the final drug/vehicle injection, both groups of rats were given a drug challenge that consisted of a single injection of $d$-amphetamine $(2 \mathrm{mg} / \mathrm{kg}$, i.p.) in their home cage, in order to determine if behavioral and neurohormonal sensitization of the HPA axis to $d$-amphetamine had occurred in the group that had previously received drug. Levels of behavioral activity were monitored prior to and every $10 \mathrm{~min}$ after the drug challenge, for $30 \mathrm{~min}$. Behavioral activation was scored according to the stereotypy rating scale of MacLennan and Maier (1983) (Table 1), and consisted of the predominant behavior during a 30 sec period, every 10 mins. This allowed us to measure baseline levels of behavior prior to drug injection, as well as the progression of the behavioral stereotypy over time. The behavior of the animals was scored by an experienced observer, in a quasi-random manner: the same experimenter scored the animals' behavior who had injected them two weeks previously, in order to minimize the potential stress to the animals. However, animals were not housed in a systematic manner, and the experimenter was unaware of the animals' prior treatment at the time of behavioral scoring; furthermore, the difference in behavior between treatment groups was largely qualitative and thus less subject to experimenter bias. Thirty min after the drug injection, animals were quietly removed from the housing colony in pairs, in counterbalanced order, and quickly decapitated. All animal handling procedures were conducted between 8 and 10:30 A.M., when rats' CORT levels are at their nadir. Trunk blood was collected and analyzed as described in Experiment 1 . It should be noted that no additional rats were challenged with vehicle instead of $d$-amphetamine, as the results of Experiment 1 indicated no effect of prior exposure to $d$-amphetamine on basal levels of ACTH and CORT (see Results).

\section{Statistical Analysis}

In Experiment 1, body weights of animals were subjected to a 2-factor repeated measures Analysis of Variance (ANOVA), with drug condition and stress as the two factors, measured across time. Organ weights of the individual rats, expressed as relative weight (organ weight/100g of body weight), were subjected to a drug $X$ stress condition ANOVA. ACTH and CORT values were similarly subjected to drug $X$ stress ANOVAS. Significant main and interaction effects were analyzed using Tukey's post-hoc tests.

In Experiment 2, behavioral activity scores prior to and after the drug challenge were subjected to a 1-factor ANOVA, with drug condition as the factor, measured across time. Significant main and interaction effects were analyzed using Tukey's post-hoc tests. ACTH and CORT values were subjected to independent samples t-tests.

Table 1. Behavioral Activation Score, Based upon Stereotypy Rating Table of MacLennan and Maier (1983)

\begin{tabular}{ll}
\hline Score & \multicolumn{1}{c}{ Behavior } \\
\hline 0 & Inactive \\
1 & Intermittent activity \\
2 & Continuous activity \\
3 & Stereotypic rearing \\
4 & Intermittent stereotypic sniffing and/or head \\
& movements \\
5 & Continuous stereotypic sniffing and/or repetitive head \\
6 & movements \\
& Continuous and restricted sniffing and/or repetitive \\
\end{tabular}




\section{RESULTS}

In Experiment 1, analyses of hormone measures indicated significant main effects of stress condition $\left(\mathrm{F}_{(1,36)}=\right.$ 213.47, $p<.001)$ and drug treatment $\left(\mathrm{F}_{(1,36)}=6.45, p<\right.$ $.05)$, and a significant stress $X$ drug treatment interaction $\left(\mathrm{F}_{(1,36)}=4.57, p<.05\right)$. Post-hoc analysis of the interaction revealed that in the non-stressed or basal condition, CORT levels in $d$-amphetamine-treated rats did not differ significantly from those in vehicle-treated rats (Figure 1, Panel A). In contrast, although both $d$-amphetamine- and vehicle-treated rats showed marked CORT increases in response to restraint stress, $d$-amphetaminetreated rats exhibited significantly higher levels of CORT $(55.47 \pm 3.14 \mu \mathrm{g} / \mathrm{dL})$ after stress than vehicle-treated animals $(40.78 \pm 3.14 \mu \mathrm{g} / \mathrm{dL}$ ) (Figure 1, Panel A). These results indicate that pretreatment with $d$-amphetamine augments the release of CORT in response to a stressor, without altering basal levels.

The effects of pretreatment with $d$-amphetamine on basal and stress-induced levels of ACTH showed a pattern of results similar to those found with CORT (Figure 1, Panel B). Significant main effects of stress condi-
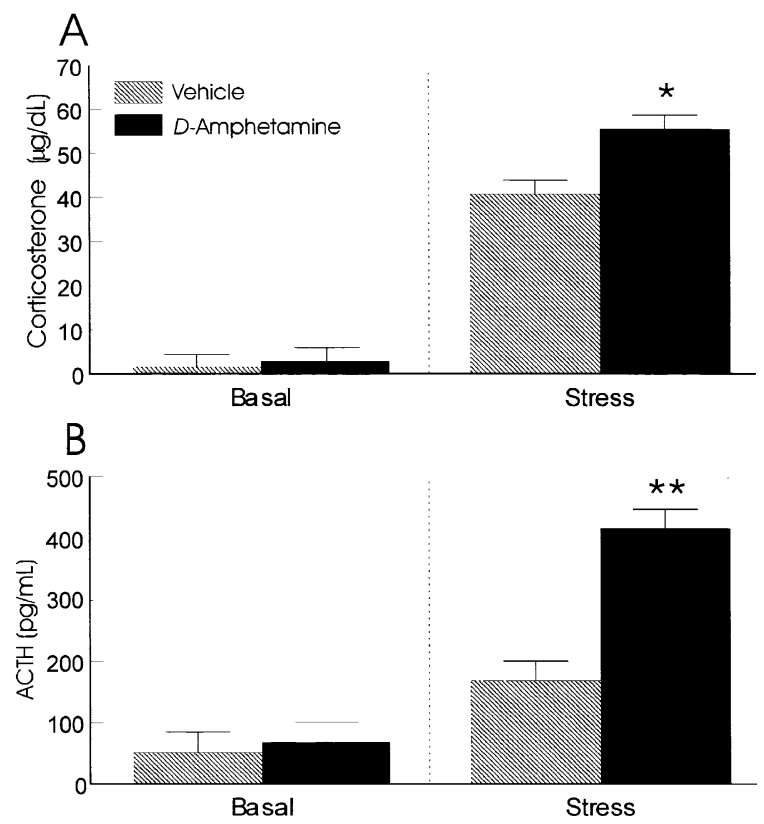

Figure 1. Panel A: The effect of pretreatment with saline vehicle (crossed bars) or $d$-amphetamine $(2 \mathrm{mg} / \mathrm{kg} \times 7$ days $+4 \mathrm{mg} / \mathrm{kg} \times 7$ days) (solid black bars) on levels of CORT after either no stress or $30 \mathrm{~min}$ of restraint stress (separate groups of animals). * denotes significantly different from vehicle-treated rats, $p<.05$. Panel B: The effect of pretreatment with saline vehicle (crossed bars) or $d$-amphetamine $(2 \mathrm{mg} / \mathrm{kg} \times 7$ days $+4 \mathrm{mg} / \mathrm{kg} \times 7$ days) (solid black bars) on levels of ACTH after either no stress or $30 \mathrm{~min}$ of restraint stress (separate groups of animals). ${ }^{* *}$ denotes significantly different from vehicle-treated rats, $p<.005$. Values represent group means ( \pm S.E.M.). tion $\left(\mathrm{F}_{(1,35)}=46.95, p<.001\right)$ and drug-treatment $\left(\mathrm{F}_{(1,35)}=\right.$ $18.55, p<.001)$, and a stress $\mathrm{X}$ drug interaction $\left(\mathrm{F}_{(1,35)}=\right.$ $10.70, p<.005)$ were observed. Post-hoc testing revealed different effects of drug treatment on basal and stress-induced levels of ACTH. For the non-stressed animals, plasma ACTH levels did not differ significantly in $d$-amphetamine and vehicle-treated subjects. However, stress-induced levels of ACTH were almost $250 \%$ greater than vehicle-treated animals, an effect that was highly significant.

Analysis of organ weights, adjusted for body weights (Table 2), revealed no significant main effects of stress or drug treatment on the thymus. There was a non-significant effect of drug treatment $\left(\mathrm{F}_{(1,35)}=3.24, p=.08\right)$ on the adrenal gland weights, which reflected slightly larger adrenals in $d$-amphetamine treated than in vehicle-treated rats $(12.95 \pm 0.62 \mathrm{mg} / 100 \mathrm{~g}$ vs $11.35 \pm 0.64$ $\mathrm{mg} / 100 \mathrm{~g}$, respectively). In contrast, the ANOVA indicated a significant main effect of drug treatment $\left(\mathrm{F}_{(1,35)}=\right.$ $5.41, p<.05)$ on relative spleen weights. Pretreatment with $d$-amphetamine was associated with lower spleen weights compared to those in vehicle-treated animals (202 $\pm 5 \mathrm{mg} / 100 \mathrm{~g}$ vs $220 \pm 6 \mathrm{mg} / 100 \mathrm{~g}$ ).

Analysis of the body weights over the four weeks of the study indicated a significant main effect of time $\left(\mathrm{F}_{(3,108)}=736.17, p<.001\right)$, but no effects of stress or drug-treatments $\left(\mathrm{F}_{(1,36)}=2.07, \mathrm{NS}\right)$.

In Experiment 2, analysis of the behavioral effects of the $d$-amphetamine challenge with the repeated-measures ANOVA indicated a significant main effect of drug treatment on behavioral stereotypy $\left(\mathrm{F}_{(1,18)}=10.24\right.$, $p=.005)$. The ANOVA also revealed a significant effect of time $\left(\mathrm{F}_{(3,54)}=143.18, p<.001\right)$ and a significant drug $X$ time interaction $\left(\mathrm{F}_{(3,54)}=3.90, p<.05\right)$, whereby animals that had been previously treated with $d$-amphetamine exhibited significantly higher stereotypy scores upon drug challenge than those that had been treated previously with only vehicle (Figure 2 ).

Analysis of the levels of CORT in $d$-amphetamine and vehicle-pretreated rats $30 \mathrm{~min}$ after the challenge with $d$-amphetamine indicated that CORT levels were significantly higher in rats that had been previously exposed to

Table 2. Effects of Treatment with $d$-amphetamine or Vehicle for 14 Days on Various Body Organs, Adjusted for Individual Body Weight. Organs Were Removed from Animals 14 days after the Last Injection. Values Represent Mean Organ Weight (mg)/100 g Body Weight ( \pm S.E.M.)

\begin{tabular}{lcc}
\hline & Vehicle & $d$-Amphetamine \\
\hline Thymus & $171( \pm 5)$ & $173( \pm 5)$ \\
Adrenal & $11.4( \pm 0.6)$ & $13.0( \pm 0.6) \#$ \\
Spleen & $220( \pm 6)$ & $202( \pm 5)^{*}$ \\
\hline
\end{tabular}

\#Denotes marginally significant difference $(0.05<p<0.10)$

${ }^{*}$ Denotes significant difference between groups $(p<0.05)$. 


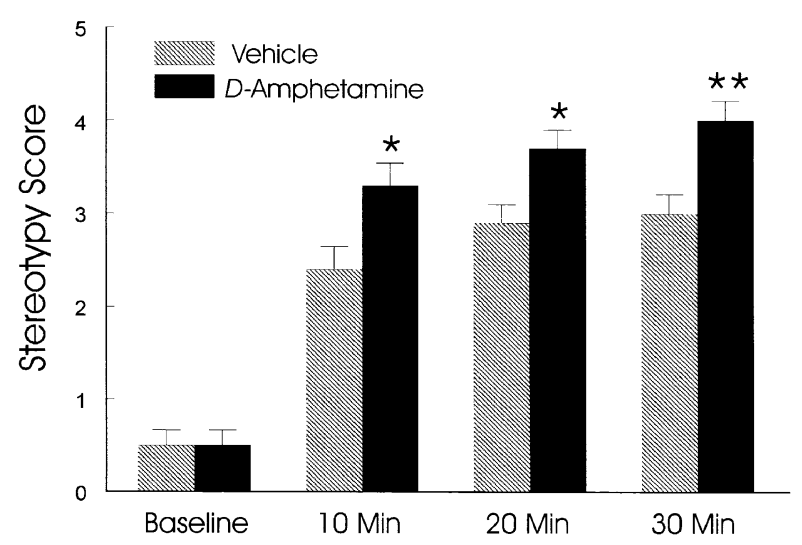

Figure 2. The effect of pretreatment with saline vehicle (crossed bars) or $d$-amphetamine $(2 \mathrm{mg} / \mathrm{kg} \times 7$ days $+4 \mathrm{mg} /$ $\mathrm{kg} \times 7$ days) (solid, black bars) on behavioral activity after a challenge injection with $d$-amphetamine $(2 \mathrm{mg} / \mathrm{kg}$, i.p.), based upon stereotypy rating scale of MacLennan and Maier (1983). * denotes significantly different from vehicle-treated rats, $p<$ .05. ${ }^{* *}$ denotes significantly different from vehicle-treated rats, $p<.005$. Values represent group means ( \pm S.E.M.).

$d$-amphetamine $\left(t_{(18)}=3.68, p<.005\right)$. Indeed, levels of CORT in $d$-amphetamine pretreated animals were almost double those of the control group $(42.40 \pm 3.52 \mu \mathrm{g} / \mathrm{dL}$ vs $22.32 \pm 3.52 \mu \mathrm{g} / \mathrm{dL}$ ) (Figure 3, Panel A). Levels of ACTH were also marginally higher in $d$-amphetamine pretreated animals than in controls $(362.39 \pm 46.83 \mathrm{pg} / \mathrm{mL}$ vs. $207.98 \pm 46.83 \mathrm{pg} / \mathrm{mL}),\left(t_{(18)}=1.73, p=.10\right)$ (Figure 3, Panel B).

\section{DISCUSSION}

Data from the present study confirm that prior exposure to $d$-amphetamine can "sensitize" the HPA axis to a subsequent challenge with the same drug. The data also demonstrate for the first time that cross-sensitization of the HPA-axis can occur between previous exposure to $d$-amphetamine and a subsequent stressor, such as restraint stress. Control animals showed the expected increase in plasma levels of CORT and ACTH following 30-in restraint stress (Kim et al. 1996; McEwen 1998), but pretreatment with $d$-amphetamine on a sensitizing schedule resulted in a greatly augmented release of CORT (+ $36 \%$ ) and $\mathrm{ACTH}(+245 \%)$ after exposure to the stressor, compared to that in vehicle-treated animals. In addition, exposure to this sensitizing schedule of $d$-amphetamine caused a slight increase in adrenal weights, as well as a significant decrease in spleen weights.

The present data are in general agreement with data from other studies that have examined the link between hormones of the HPA-axis and psychostimulant sensitization. For example, following exposure to intermittent cocaine, it was found that a subsequent challenge with the same drug augmented the release of both CORT
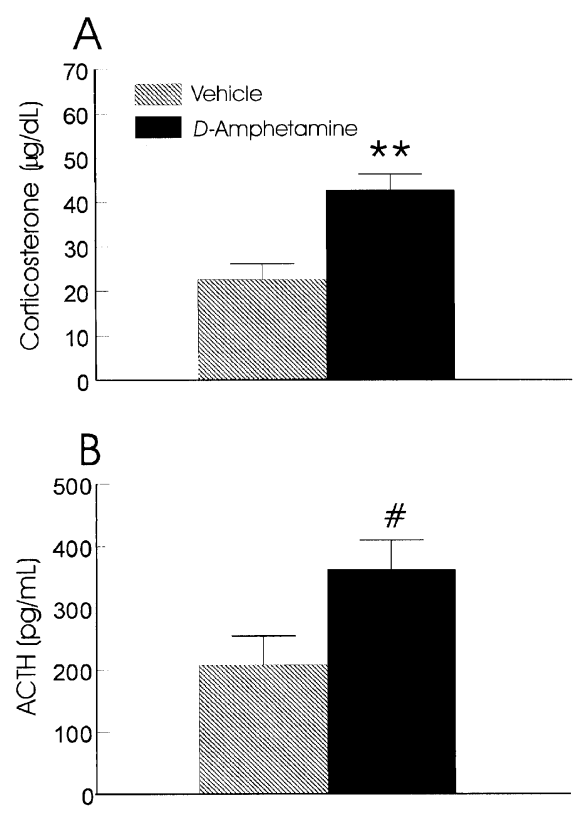

Figure 3. Panel A: The effect of pretreatment with saline vehicle (crossed bars) or $d$-amphetamine $(2 \mathrm{mg} / \mathrm{kg} \times 7$ days + $4 \mathrm{mg} / \mathrm{kg} \times 7$ days) (solid black bars) on levels of CORT after a challenge injection with $d$-amphetamine $(2 \mathrm{mg} / \mathrm{kg}$, i.p.). ** denotes significantly different from vehicle-treated rats, $p<$ .005. Panel B: The effect of pretreatment with saline vehicle (crossed bars) or $d$-amphetamine $(2 \mathrm{mg} / \mathrm{kg} \times 7$ days $+4 \mathrm{mg} /$ $\mathrm{kg} \times 7$ days) (solid black bars) on levels of ACTH after a challenge injection with $d$-amphetamine $(2 \mathrm{mg} / \mathrm{kg}$, i.p.). \# denotes marginal significance from vehicle-treated rats, $p=.10$. Values represent group means ( \pm S.E.M.).

and ACTH in sensitized animals to a greater degree than in non-sensitized rats (Schmidt et al. 1995). This effect was recently replicated, using a single exposure to $d$-amphetamine as the sensitizing stimulus (Vanderschuren et al. 1999). Thus, the augmented increases in CORT and ACTH that were observed in $d$-amphetamine pretreated rats in response to a drug challenge in the present study confirm the findings of Vanderschuren et al.(1999), and also demonstrate that a more chronic schedule of $d$-amphetamine administration produces similar effects. Cross-sensitization of the HPA-axis between $d$-amphetamine and stress has been shown to occur when animals were initially exposed to different stressors, and then subjected to a $d$-amphetamine challenge (Schmidt et al. 1999), which is the converse of our novel findings.

In apparent contrast to the present data, a recent experiment by Sarnyai et al. (1998) failed to detect differences in stress-induced levels of CORT following 60 min of restraint stress in rats that had been previously administered chronic cocaine, compared to control animals. In addition, their study observed increased levels of CORT in the cocaine-treated compared to the vehicle-treated animals in the non-stressed condition. These results appear to be contrary to our findings, in which 
we demonstrated that basal levels of CORT and ACTH did not differ in $d$-amphetamine-treated compared to vehicle-treated rats in the nonstressed condition, but that stress-induced levels were differentially elevated. The discrepancy in these findings may be attributable to a number of different factors. The study by Sarnyai et al. (1998) utilized a "binge" protocol of cocaine administration that consisted of multiple daily injections of the drug, whereas we used a regimen that was designed to induce sensitization, and was comprised of single daily injections. Previous work has shown that the behavioral and neurochemical effects of drug administration differ significantly depending upon the pattern of administration (Segal and Kuczenski 1997; Lin et al. 2000). In addition, rats in the previous study were subjected to restraint stress the day after their final injection of cocaine. This period probably reflects a time when the animals are experiencing the psychological effects of drug withdrawal, (Markou and Koob 1991; Mutschler and Miczek 1998) and compensatory homeostatic mechanisms are engaged to restore a post-binge equilibrium (Koob et al. 1997). In contrast, animals in the present study were allowed to recover from the drug for two weeks, and thus tested at a time at when the effects of psychostimulant sensitization are most pronounced (Paulson et al. 1991). Furthermore, animals in the study by Sarnyai et al. were exposed to stress for twice as long as in the present study, indicating that HPA activity was being measured at different timepoints, and thus possibly during a different phase of glucocorticoid activation and/or glucocorticoid-mediated feedback.

The molecular mechanisms by which pretreatment with $d$-amphetamine leads to sensitization of the HPA axis to subsequent drug or stress challenges were not addressed by the present study. However, several important recent studies have reported data that may provide insight into the molecular mechanisms that are involved. It is unlikely that the mild adrenal hypertrophy observed in $d$-amphetamine sensitized rats would be the primary cause of HPA hyperreactivity, as the increase in adrenal weights was slight compared to the large increases in CORT observed in response to a drug or stressor challenge. Additionally, the increased levels of ACTH in $d$-amphetamine pretreated animals are suggestive of alterations at the level of the pituitary. An earlier study by Robinson et al. (1987) observed that $d$-amphetaminesensitized rats exhibited greater levels of pituitary $\beta$-endorphin release in response to a footshock stressor, which parallels the increases in ACTH release that we observed. The exact nature of increased neuropeptide hormone release is unclear, but may be related to alterations in the normal glucocorticoid inhibitory feedback system.

One of the most important sites of feedback is the hippocampus (Jacobson and Sapolsky 1991; Young and Vazquez 1996), wherein Type I (mineralocorticoid) CORT receptors modulate primarily basal or tonic levels of CORT, while Type II (glucocorticoid) receptors play a key role in the inhibitory feedback following stress-induced CORT elevations. Several recent studies have reported that exposure of rats to sensitizing schedules of $d$-amphetamine results in selective down-regulation of glucocorticoid, but not mineralocorticoid, receptors in the hippocampus (Budziszewska et al. 1995; Shilling et al. 1996; Trovero et al. 1999). These findings are entirely consistent with the results of the present study, as we failed to observe an effect of pretreatment with $d$-amphetamine on basal levels of CORT, which are mediated by mineralocorticoid receptors and remain unaffected by exposure to $d$-amphetamine. In contrast, the elevated levels of CORT in $d$-amphetamine pretreated animals following restraint stress could be explained by down-regulated levels of glucocorticoid receptors and an ensuing selective deficit in glucocorticoid mediated inhibition of stress or drugrelated levels of CORT and ACTH. Other potential mediators of a sensitized HPA axis could include the locus ceruleus (LC)/hypothalamic paraventricular nucleus (PVN) system. Noradrenergic neurons of the LC are sensitized by exposure to chronic amphetamine (Harris and Williams 1992), and these neurons provide a major excitatory input to the corticotropin-releasing hormone (CRH)-containing neurons of the PVN (Day et al. 1999). As CRH has been shown to mediate psychostimulant-induced behavioral sensitization (Cole et al. 1990; Cador et al. 1992), further research is required to determine if this system is also involved in HPA axis sensitization to $d$-amphetamine.

While it is generally agreed that the hormones of the HPA axis perform an essential function in the adaptation of animals to the acute effects of stress (Sapolsky et al. 2000), there has been renewed interest in the deleterious effects of alterations in the regulation of this system. McEwen and Koob, amongst others, have suggested that excessive and inappropriate levels of corticosteroids over an extended period can exceed the organism's capacity to deal with them effectively (McEwen 1998,2000; Koob and Le Moal 2001). The resulting "allostatic load" can lead to a host of harmful somatic and psychiatric symptoms, as well as damage to regions of the brain such as the hippocampus (Brown et al. 1999). As the neurochemical effects of psychostimulant sensitization in animals are typically long lasting (Paulson et al. 1991; Castner and Goldman-Rakic 1999), the results of the present study may allow for a further refinement in the model of "allostatic load". It is predicted that psychostimulantsensitized animals or humans would exhibit elevated levels of corticosteroids in response to mild stressors; if these stressors were repeated on a regular basis, they could exceed the homeostatic capacity and result in the type of toxic effects that have been described. Glucocorticoids also exhibit a well-known immunosuppressive effect (De Bosscher et al. 2000), and chronically elevated levels of these hormones may be responsible for the reduced spleen weights that we observed in $d$-amphetamine pretreated animals, which would be consistent 
with the literature on immunosuppressive effects of chronic amphetamine (House et al. 1994; Basso et al. 1999). Human psychostimulant abusers show a higher degree of morbidity than the general population (Cregler 1989), and the results of the present study suggest that alterations in the activity of the HPA axis in response to stress might be one factor responsible for this effect. Many human drug addicts who abuse psychostimulants also exhibit an increased reactivity to stress (Keller and Wilson 1994; Wills et al. 1996), which is often self-medicated through further substance abuse (Markou et al. 1998). Animal models of drug addiction have demonstrated that stress can be an important factor in determining the amount of drug that is consumed, as well as increasing the probability of acquiring drug self-administration and relapsing during extinction (Haney et al. 1995; Erb et al. 1996; Tidey and Miczek 1997). As circulating levels of glucocorticoids play an important role in drug self-administration (Deroche et al. 1997; Mantsch et al. 1998), the elevated levels of these hormones in sensitized animals may contribute to the effects of stress on drug selfadministration. In theory, this effect could be achieved by either lowering the threshold of stress that would be required to initiate or maintain drug administration (requiring a less intense stressor to attain a hypothesized "critical" level of CORT), or lengthening the duration of the effects of stress on the HPA axis, and subsequently increasing the interval of vulnerability to self-administration.

Endogenous processes resembling neurochemical sensitization have also been hypothesized to underlie the development of psychiatric disorders, including schizophrenia (Lieberman et al. 1997; Laruelle 2000) and Major Depressive Disorder (Post 1992). HPA axis abnormalities have been widely reported in sub-populations of both of these psychiatric disorders (Plotsky et al. 1998; MuckSeler et al. 1999; Heim et al. 2000). The findings of the present study suggest that a clearer understanding of the mechanisms by which drugs such as $d$-amphetamine induce sensitization of the HPA axis to stressors may provide further insight into the development of psychiatric disorders as well as current models of allostasis.

\section{ACKNOWLEDGMENTS}

This research was made possible by a grant from the Canadian Institutes of Health Research to AGP, from the National Institute on Alcohol Abuse and Alcoholism grant AA07789 to JW, and an Alberta Heritage Foundation for Medical Research Scholarship to CEH.

\section{REFERENCES}

Antelman SM, Eichler AJ, Black CA, Kocan D (1980): Interchangeability of stress and amphetamine in sensitization. Science 207:329-331
Badiani A, Jakob A, Rodaros D, Stewart J (1996): Sensitization of stress-induced feeding in rats repeatedly exposed to brief restraint: the role of corticosterone. Brain Res 710:35-44

Basso AM, Gioino G, Molina VA, Cancela LM (1999): Chronic amphetamine facilitates immunosuppression in response to a novel aversive stimulus: reversal by haloperidol pretreatment. Pharmacol Biochem Behav 62:307-314

Brown ES, Rush AJ, McEwen BS (1999): Hippocampal remodeling and damage by corticosteroids: implications for mood disorders. Neuropsychopharmacology 21:474-484

Budziszewska B, Jaworska-Feil L, Lason (1995): Repeated amphetamine administration down-regulates glucocorticoid, but not mineralocorticoid, receptors in the hippocampus. Pol J Pharmacol 47:401-406

Cador M, Dumas S, Cole BJ, Mallet J, Koob GF, Le Moal M, Stinus L (1992): Behavioral sensitization induced by psychostimulants or stress: search for a molecular basis and evidence for a CRF-dependent phenomenon. Ann N Y Acad Sci 654:416-420

Castner SA, Goldman-Rakic PS (1999): Long-lasting psychotomimetic consequences of repeated low-dose amphetamine exposure in rhesus monkeys. Neuropsychopharmacology20:10-28

Cole BJ, Cador M, Stinus L, Rivier C, Rivier J, Vale W, Le Moal M, Koob GF (1990): Critical role of the hypothalamic pituitary adrenal axis in amphetamine-induced sensitization of behavior. Life Sci 47:1715-1720

Cregler LL (1989): Adverse health consequences of cocaine abuse. J Natl Med Assoc 81:27-38

Day HE, Campeau S, Watson SJ Jr, Akil H (1999): Expression of alpha(1b) adrenoceptor mRNA in corticotropinreleasing hormone-containing cells of the rat hypothalamus and its regulation by corticosterone. J Neurosci 19:10098-10106

Day JC, Koehl M, Deroche V, Le Moal M, Maccari S (1998): Prenatal stress enhances stress- and corticotropinreleasing factor-induced stimulation of hippocampal acetylcholine release in adult rats. J Neurosci 18:18861892

De Bosscher K, Vanden Berghe W, Haegeman G (2000): Mechanisms of anti-inflammatory action and of immunosuppression by glucocorticoids: negative interference of activated glucocorticoid receptor with transcription factors. J Neuroimmunol 109:16-22

Deroche V, Marinelli M, Le Moal M, Piazza PV (1997): Glucocorticoids and behavioral effects of psychostimulants. II: cocaine intravenous self-administration and reinstatement depend on glucocorticoid levels. J Pharmacol Exp Ther 281:1401-1407

Dohrenwend BP (2000): The role of adversity and stress in psychopathology: some evidence and its implications for theory and research. J Health Soc Behav 41:1-19

Duncan GE, Sheitman BB, Lieberman JA (1999): An integrated view of pathophysiological models of schizophrenia. Brain Res Brain Res Rev 29:250-264

Ehlert U, Straub R (1998): Physiological and emotional response to psychological stressors in psychiatric and psychosomatic disorders. Ann N Y Acad Sci 851:477-486 
Erb S, Shaham Y, Stewart J (1996): Stress reinstates cocaineseeking behavior after prolonged extinction and a drugfree period. Psychopharmacology 128:408-412

Folkow B (1997): Physiological aspects of the "defence" and "defeat" reactions. Acta Physiol Scand Suppl 640:34-7

Goldstein DS (1990): Neurotransmitters and stress. Biofeedback Self Regul 15:243-271

Hamamura T, Fibiger HC (1993): Enhanced stress-induced dopamine release in the prefrontal cortex of amphetamine-sensitized rats. Eur J Pharmacol 237:65-71

Haney M, Maccari S, Le Moal M, Simon H, Piazza PV (1995): Social stress increases the acquisition of cocaine self-administration in male and female rats. Brain Res 698:46-52

Harris GC, Williams JT (1992): Sensitization of locus ceruleus neurons during withdrawal from chronic stimulants and antidepressants. J Pharmacol Exp Ther 261: 476-483

Heim C, Newport DJ, Heit S, Graham YP, Wilcox M, Bonsall R, Miller AH, Nemeroff CB (2000): Pituitary-adrenal and autonomic responses to stress in women after sexual and physical abuse in childhood. JAMA 284:592-597

Henry JP (1992): Biological basis of the stress response. Integr Physiol Behav Sci 27:66-83

House RV, Thomas PT, Bhargava HN (1994): Comparison of immune functional parameters following in vitro exposure to natural and synthetic amphetamines. Immunopharmacol Immunotoxicol 16:1-21

Jacobson L, Sapolsky R (1991): The role of the hippocampus in feedback regulation of the hypothalamic-pituitaryadrenocortical axis. Endocr Rev 12:118-134

Johnson EO, Kamilaris TC, Chrousos GP, Gold PW (1992): Mechanisms of stress: a dynamic overview of hormonal and behavioral homeostasis. Neurosci Biobehav Rev 16:115-130

Kaneko M, Kaneko K, Shinsako J, Dallman MF (1981): Adrenal sensitivity to adrenocorticotropin varies diurnally. Endocrinology 109:70-75

Keller DS, Wilson A (1994): Affectivity in cocaine and opiate abusers. Psychiatry 57:333-347

Kim CK, Osborn JA, Weinberg J (1996): Stress reactivity in fetal alcohol syndrome. In Abel EL (ed), Fetal Alcohol Syndrome: from Mechanism to Prevention. Boca Raton, CRC Press, pp 215-235

Koob GF, Caine SB, Parsons L, Markou A, Weiss F (1997): Opponent process model and psychostimulant addiction. Pharmacol Biochem Behav 57:513-521

Koob GF, Le Moal M (2001): Drug addiction, dysregulation of reward, and allostasis. Neuropsychopharmacology 24:97-129

Kreek MJ, Koob GF (1998): Drug dependence: stress and dysregulation of brain reward pathways. Drug Alcohol Depend 51:23-47

Laruelle M (2000): The role of endogenous sensitization in the pathophysiology of schizophrenia: implications from recent brain imaging studies. Brain Res Brain Res Rev 31:371-384

Liang SW, Boyce WT (1993): The psychobiology of childhood stress. Curr Opin Pediatr 5:545-551

Lieberman JA, Sheitman BB, Kinon BJ (1997): Neurochemi- cal sensitization in the pathophysiology of schizophrenia: deficits and dysfunction in neuronal regulation and plasticity. Neuropsychopharmacology 17:205-229

Lin D, Koob GF, Markou A (2000): Time-dependent alterations in ICSS thresholds associated with repeated amphetamine administrations. Pharmacol Biochem Behav 65:407-417

MacLennan AJ, Maier SF (1983): Coping and the stressinduced potentiation of stimulant stereotypy in the rat. Science 219: 1091-3

Mantsch JR, Saphier D, Goeders NE (1998): Corticosterone facilitates the acquisition of cocaine self-administration in rats: opposite effects of the type II glucocorticoid receptor agonist dexamethasone. J Pharmacol Exp Ther 287:72-80

Markou A, Koob GF (1991): Postcocaine anhedonia. An animal model of cocaine withdrawal. Neuropsychopharmacology 4:17-26

Markou A, Kosten TR, Koob GF (1998): Neurobiological similarities in depression and drug dependence: a selfmedication hypothesis. Neuropsychopharmacology 18:135-174

McEwen BS (1998): Stress, adaptation, and disease. Allostasis and allostatic load. Ann N Y Acad Sci 840:833-844

McEwen BS (2000): Allostasis and allostatic load: implications for neuropsychopharmacology. Neuropsychopharmacology 22:108-124

Muck-Seler D, Pivac N, Jakovljevic M, Brzovic Z (1999): Platelet serotonin, plasma cortisol, and dexamethasone suppression test in schizophrenic patients. Biol Psychiatry 45:1433-1439

Mutschler NH, Miczek KA (1998): Withdrawal from i.v. cocaine "binges" in rats: ultrasonic distress calls and startle. Psychopharmacology 135:161-168

Pani L, Porcella A, Gessa GL (2000): The role of stress in the pathophysiology of the dopaminergic system. Mol Psychiatry 5:14-21

Paulson PE, Camp DM, Robinson TE (1991): Time course of transient behavioral depression and persistent behavioral sensitization in relation to regional brain monoamine concentrations during amphetamine withdrawal in rats. Psychopharmacology 103:480-492

Pitman DL, Ottenweller JE, Natelson BH (1990): Effect of stressor intensity on habituation and sensitization of glucocorticoid responses in rats. Behav Neurosci 104:28-36

Plotsky PM, Owens MJ, Nemeroff CB (1998): Psychoneuroendocrinology of depression. Hypothalamic-pituitary-adrenal axis. Psychiatr Clin North Am 21:293-307

Post RM (1992): Transduction of psychosocial stress into the neurobiology of recurrent affective disorder. Am J Psychiatry 149:999-1010

Prasad BM, Ulibarri C, Sorg BA (1998): Stress-induced crosssensitization to cocaine: effect of adrenalectomy and corticosterone after short- and long-term withdrawal. Psychopharmacology 136:24-33

Robinson TE, Becker JB, Young EA, Akil H, Castaneda E (1987): The effects of footshock stress on regional brain dopamine metabolism and pituitary beta-endorphin release in rats previously sensitized to amphetamine. Neuropharmacology 26:679-691 
Sapolsky RM, Romero LM, Munck AU (2000): How do glucocorticoids influence stress responses? Integrating permissive, suppressive, stimulatory, and preparative actions. Endocr Rev 21:55-89

Sarnyai Z, Dhabhar FS, McEwen BS, Kreek MJ (1998): Neuroendocrine-related effects of long-term, 'binge' cocaine administration: diminished individual differences in stress-induced corticosterone response. Neuroendocrinology 68:333-344

Schmidt ED, Tilders FJ, Binnekade R, Schoffelmeer AN, De Vries TJ (1999): Stressor- or drug-induced sensitization of the corticosterone response is not critically involved in the long-term expression of behavioural sensitization to amphetamine. Neuroscience 92:343-352

Schmidt ED, Tilders FJ, Janszen AW, Binnekade R, De Vries TJ, Schoffelmeer AN (1995): Intermittent cocaine exposure causes delayed and long-lasting sensitization of cocaine-induced ACTH secretion in rats. Eur J Pharmacol 285:317-321

Segal DS, Kuczenski R (1997): Repeated binge exposures to amphetamine and methamphetamine: behavioral and neurochemical characterization. J Pharmacol Exp Ther 282:561-573

Shilling PD, Kelsoe JR, Segal DS (1996): Hippocampal glucocorticoid receptor mRNA is up-regulated by acute and down-regulated by chronic amphetamine treatment. Mol Brain Res 38:156-160
Tidey JW, Miczek KA (1997): Acquisition of cocaine selfadministration after social stress: role of accumbens dopamine. Psychopharmacology 130:203-212

Trovero F, Brochet D, Tassin J, Drieu K (1999): Ginkgo biloba extract Egb761 reduces the development of amphetamine-induced behavioral sensitization: effects on hippocampal type II corticosteroid receptors. Brain Res 818:135-139

Vanderschuren LJ, Schmidt ED, De Vries TJ, Van Moorsel CA, Tilders FJ, Schoffelmeer AN (1999): A single exposure to amphetamine is sufficient to induce long-term behavioral, neuroendocrine, and neurochemical sensitization in rats. J Neurosci 19:9579-9586

Weinberg J, Bezio S (1987): Alcohol-induced changes in pituitary-adrenal activity during pregnancy. Alcohol Clin Exp Res 11:274-280

Weinberg J, Taylor AN, Gianoulakis C (1996): Fetal ethanol exposure: hypothalamic-pituitary-adrenal and betaendorphin responses to repeated stress. Alcohol Clin Exp Res 20:122-131

Wills TA, Vaccaro D, McNamara G, Hirky AE (1996): Escalated substance use: a longitudinal grouping analysis from early to middle adolescence. J Abnorm Psychol 105:166-180

Young EA, Vazquez D (1996): Hypercortisolemia, hippocampal glucocorticoid receptors, and fast feedback. Mol Psychiatry 1:149-159 